\title{
Gonçalo M. Tavares, uma viagem ao valor com Camões ao fundo e alguns problemas contemporâneos
}

\author{
LUIS MAFFEI \\ Universidade Federal Fluminense (Niterói, Brasil)
}

RESUMO: EM 2010, GONÇALO M. TAVARES EDITA UMA VIAGEM À ÍNDIA - MELANCOLIA CONTEMPORÂNEA (UM ITINERÁRIO), POEMA QUE SE CONSTRÓI NUM DIÁLOGO FRANCO COM OS LUSÍADAS. AO LEITOR DESSA CONTEMPORÂNEA AVENTURA LITERÁRIA EXIGE-SE, PARA ALÉM DO ESPELHAMENTO ENTRE A OBRA NOVA E A DE CAMÕES, UM OLHAR MUITO ATENTO PARA CERTA QUESTÃO-CHAVE: O PAPEL DO DINHEIRO EM NOSSO TEMPO, E SUA RELAÇÃO TENSA COM A OBRA DE ARTE, AINDA MAIS POR GONÇALO M. TAVARES DESFRUTAR DE GRANDE PRESTÍGIO NO MERCADO EDITORIAL.

ABSTRACT: IN 2010, GONÇALO M. TAVARES EDITED UMA VIAGEM À ÍNDIA - MELANCOLIA CONTEMPORÂNEA (UM ITINERÁRIO), POEM WHICH CONSTRUCTS ITSELF IN A FRANK DIALOGUE WITH OS LUSÍADAS. FOR THE READER OF THIS CONTEMPORARY LITERARY ADVENTURE IS REQUIRED, IN ADDITION TO THE MIRROR BETWEEN THE NEW WORK AND CAMÕES'S WORK, A VERY CAREFUL LOOK TO A CERTAIN KEY ISSUE: THE ROLE OF MONEY IN OUR TIME. BY THE WAY, GONÇALO M. TAVARES ENJOYS ENORMOUS PRESTIGE IN PUBLISHING MARKET.

PALAVRAS-CHAVE: GONÇALO M. TAVARES, VALOR, DINHEIRO, CAMÕES, OS LUSÍADAS. KEYWORDS: GONÇALO M. TAVARES, VALUE, MONEY, CAMÕES, OS LUSÍADAS. 
ertas palavras do prefácio de Eduardo Lourenço a Uma viagem à Índia: melancolia contemporânea (um itinerário) podem ser de grande utilidade para a leitura da obra, pois o crítico refere-se a "uma devastadora e radical ironia que em permanência desloca o texto para paragens não percorridas" (LOURENÇO, 2010, p. 14). Este ensaio desembocará na questão do dinheiro, e numa necessária problematização do literário face à presença da vasta e desfacetada instância chamada mercado. Mas sem pressa, pois há itinerário, arriscado, mas itinerário. Primeira paragem: ironia. Diz Herberto Helder, no fecho de "(cumplicidades menores)", texto de Photomaton \& vox: "A ironia não salva, mas ressalva" (HELDER, 1995, p. 30). Que haveria para ser salvo no poema de Gonçalo? O objetivo mesmo da viagem de Bloom:

Falaremos da hostilidade que Bloom,

o nosso herói,

revelou em relação ao passado,

levantando-se e partindo de Lisboa

numa viagem à Índia, em que procurou sabedoria

e esquecimento.

E falaremos do modo como na viagem

levou um segredo e o trouxe, depois, quase intacto.

(TAVARES, 2010, p. 32)

Palavras-chave, "sabedoria/ e esquecimento". Mas, de acordo com Herberto Helder, a "ironia não salva, mas ressalva". Assim, "o nosso herói” nada salvará em sua viagem, tampouco a si mesmo, tampouco a "sabedoria" ou o "esquecimento". Que quer esquecer Bloom? Decerto Alguns episódios, como a perpetração, por seu próprio pai, do assassinato de sua amada, e a vingança a isso, que foi o assassinato do pai pelo próprio Bloom. Noutro plano, que poderá querer esquecer e lembrar a própria existência de Uma viagem à India? Certa memória profunda, indelével, com gosto a glória e a derrota, de nome Os Lusíadas. Ler Gonçalo exige ter Camões ao pé - em virtude de cada Canto do texto recente possuir idêntica quantidade de estrofes que cada Canto d'Os Lusíadas, por haver efetiva recuperação de versos e claro espelhamento entre episódios de um e outro poema. 
Antes de qualquer referência direta a Camões, outra ironia, que procurarei problematizar tendo em conta o que leio nas duas últimas estrofes do Canto X:

A ingenuidade é irrecuperável.

Bloom está em cima de uma ponte alta

e a noite esconde

os sapatos pretos. Nenhuma excitação

no homem que regressou ao ponto de partida.

Há várias maneiras de um corpo se matar,

e cair do alto sobre a água é uma delas.

Uma mulher, entretanto, aproxima-se.

Bloom vira a cabeça: é uma mulher bonita, que sorri.

Não quer conversar?, pergunta ela. Bloom encolhe os

ombros.

Ninguém em redor, silêncio completo, a água

lá em baixo, por vezes um carro.

Põe a mão no bolso: o velho rádio do pai nem

com a viagem voltou a funcionar.

Ele aproxima-se da mulher e o mundo prossegue,

mas nada que aconteça poderá impedir o definitivo tédio de

Bloom, o nosso herói.

(TAVARES, 2010, p. 455, 456)

A ironia é sugestiva (nalgum ponto deste texto falarei de mais uma ironia, esta extratexual): de volta à mesma Lisboa de onde partira, sem nada, nem "sabedoria" nem "esquecimento", nem sequer o "velho rádio do pai" assassinado, tendo voltado a funcionar, "o nosso herói" pensa em se matar sobre uma ponte, cujo nome talvez seja Vasco da Gama - a oposição entre o herói d'Os Lusíadas e o de Gonçalo é tanta e tão basilar que sequer precisa ser formulada. Bloom condensa o que no épico camoniano atinge várias diferentes personagens, o que é um dos traços de pluralidade, ou polifonia, para recuperar o conceito bakhtiniano, do poema de Camões. Por outro lado, Bloom revive pastiches de peripécias vivenciadas pelo Gama, por Pedro, pelo Poeta, etc. 
Isso não sugere lisura no que tange à narratividade de Uma viagem à Índia, pois o narrador do texto de Gonçalo não se mostra distenso. Na estrofe 119 do Canto III, lê-se, quando é descrito o amor de Pedro por Inês, ou melhor, o amor de Bloom por Mary: "Mas o certo é que Bloom/ - deixe-me falar de mim como se eu fosse um outro -/ Bloom era, nessa altura, unilateral e o seu único lado/ era este: o lado virado para Mary.” (TAVARES, 2010, p. 157). Como ler essa diferença narrativa? Pelo viés da ironia? Talvez pudesse ser produtiva a escolha, mas vou por outro caminho: se há traços de um projeto renascentista na obra camoniana, eles se mostram sobremaneira numa vontade generosa de abrangência que tangencia até mesmo o cósmico - vejo a Máquina do Mundo como exemplo disso, pois, diante dela, entre outras maravilhas fatais, passa-se por Deus, ainda que calando sobre Ele, num contexto conversacional que reúne uma ninfa e um humano.

Recuperei a ideia de polifonia que Bakhtin aplicava a certo tipo de romance porque, não apenas em Dostoievski, mas n’Os Lusiadas são notáveis “a multiplicidade de vozes e consciências independentes e imiscíveis e a autêntica polifonia de vozes plenivalentes" (BAKHTIN, 2002, p. 4). É certo que, no poema camoniano, é possível apontar, não para qualquer óbvia prevalência, mas para a sobrelevação de uma espécie de utopia báquico-amorosa. Não obstante, há múltiplas vozes no épico camoniano, que, não raro, se mostram "imiscíveis".

No caso do texto de Gonçalo, tal gana não se presentifica, nem se poderia presentificar, "Melancolia contemporânea" de que é "itinerário". No entanto, não faria sentido que o narrador se mostrasse demasiado unívoco e o mesmo se desse com o protagonista, o que representaria uma anacrônica fé no sujeito e na subjetividade - Lourenço afirma que a "nossa fabulosa aventura foi sempre sem sujeito como os gregos já sabiam" (LOURENÇO, 2010, p. 15) e nós, contemporâneos de Bloom, somos forçados a saber.

Isso, por si só, já confere certa polifonia, ainda que de peculiar natureza, à enunciação de Uma viagem à Índia, mesmo porque, de acordo com Beth Brait, a ironia tem como traço indelével sua abertura a um discurso polifônico, já que a linguagem irônica escorrega dos semas imediatos a fim de pô-los em estado de suspeição. As primeiras estrofes do Canto I de Gonçalo propõem o tema do texto que está começando e giram sempre em torno de construções como "Falaremos de Bloom/ e da sua viagem à Índia" (TAVARES, 2010, p. 29), estrofe 1, e "Falaremos de uma viagem à Índia./ E do seu herói, Bloom" (TAVARES, 
2010, p. 32), estrofe 9, em oposição àquilo de que não se vai tratar, e nisso está a ironia: "Não falaremos do rochedo sagrado/ onde a cidade de Jerusalém foi construída", estrofe 1, "Não falaremos de heróis que se perderam/ em labirintos/ nem na demanda do Santo Graal" (TAVARES, 2010, p. 29), estrofe 3, "Não falaremos das grandes pirâmides de Gizé,/ das suas múltiplas passagens secretas / que permitem a entrada ou a fuga dos homens" (TAVARES, 2010, p. 30), estrofe 5, "Não falaremos do aparecimento súbito/ de anões em certas grutas do México,/ nem dos penhascos no Colorado/ onde dentro da pedra se construíram casas" (TAVARES, 2010, p. 31-32), estrofe 9.

Em verdade, a ironia não está apenas nas negativas, tão abarcantes que nada abarcam enquanto revelam que nada abarcam, mas, especialmente, na tensão entre negativas anchas e afirmativas apoucadas - ambas são ditas por um nós que não se encontra no assunto e sim na locução, ao contrário do que ocorre n'Os Lusíadas, em que um eu - "Cantando espalharei por toda parte,/ Se a tanto me ajudar o engenho e arte" (Lus, I, 2, 7-8) - canta um eles - "As armas e os barões assinalados" (Lus, I, 1, 1) que, em verdade, é um nós. O nós de Gonçalo é, ele mesmo, irônico, pois se assume majestático para revelar a impossibilidade, não apenas de um espírito coletivo, mas também de qualquer majestade, literal ou metafórica.

Sou remetido agora ao primeiro majestoso interlocutor moderno d'Os Lusíadas, Cesário Verde. N' "O Sentimento dum Ocidental”, um eu refere-se a um nós, assim como na magna obra de Camões, mas a identificação é impossível: "Nas nossas ruas, ao anoitecer,/ Há tal soturnidade, há tal melancolia,/ Que as sombras, o bulício, o Tejo, a maresia/ Despertam-me um desejo absurdo de sofrer." (VERDE, 2010, p. 199). Ou seja, no espaço coletivo, "nossas ruas", o "desejo absurdo de sofrer" encontra-se num sujeito apenas, quase flâneur, "ocidental" sem "praia Lusitana" (Lus, I, 1, 2), mas com "melancolia" semelhante à que se encontra no texto do século XXI. O narrador de Gonçalo M. Tavares, nós falso porque sujeito coletivo impossível, conversa com outro nós falso, o próprio Bloom, ainda com muita ironia ao tratá-lo por tu. Faz sentido citar a estrofe 33 do Canto I:

Diga-se ainda (e perdoe-se mais este desvio

- serão tantos, meu caro, prepara-te), diga-se ainda que as discussões universais dos homens 
são sempre discussões particulares. Cada qual

está debruçado sobre o mundo

em parapeito frágil.

E nem mesmo os imbecis têm fisionomias

colectivas. Cada país é um pormenor que cada habitante utiliza

como melhor lhe convém e como a lei

permite.

(TAVARES, 2010, p. 40)

Bloom se acha com um papel afim ao do leitor, já que os desvios achacamno pelo viés da digressão (traço, sabemos, marcante d'Os Lusíadas se o considerarmos um poema narrativo)? No espelhamento em que Uma viagem à Índia investe, vou a Camões e percebo que a estância 33 do Canto I é a que revela a simpatia de Vênus pela viagem do Gama. Por que motivos? "Nos fortes corações, na grande estrela/ Que mostraram na terra tingitana,/ E na língua, na qual quando imagina,/ Com pouca corrupção crê que é a latina." (Lus, I, 33, 5-8). Está em discussão a morte de Deus e dos deuses ("Decididamente, os Deuses já começam a vida/ inertes e preguiçosos" (TAVARES, 2010, p. 81), diz a estrofe que espelha o episódio em que Vênus e as nereidas protegem fisicamente a esquadra do Gama diante de uma cilada de Baco), assim como a extinção de uma mitologia que não seja de mercado - daqui a pouco esse será o tema do corrente ensaio. Também está em discussão a falência de uma perspectiva coletivizante da "língua", num poema cujo protagonista parte de Lisboa para a Índia, mas atende pelo anglo nome de Bloom.

Há vários parágrafos eu prometi tratar de certa ironia extratextual, mas ainda não é tempo. Por ora, interessa-me que nós, contemporâneos de Bloom, eu já disse, somos forçados a saber que "nossa fabulosa aventura foi sempre sem sujeito", como disse Eduardo Lourenço. No Canto X, a contemporaneidade é dita impossível: "Os humanos são novos de mais ou velhos/ de mais: ninguém consegue ser contemporâneo" (TAVARES, 2010, p. 446). A impossibilidade de se experienciar o contemporâneo tem que ver, decerto, com um tempo cada vez mais veloz, no qual se torna progressivamente menos possível o estabelecimento seguro de seguras relações - já direi da mercadoria, e do livro no contexto das mercadorias, e da tal ironia extratextual. Antes, cito Madalena Vaz-Pinto, quiçá a mais atenta leitora de Gonçalo M. Tavares no 
Brasil: "O valor dos textos de Gonçalo Tavares está no questionamento sobre o que deve ter valor, em fazer do valor uma questão, uma procura, uma experimentação. A experimentação é incompatível com a certeza." (VAZ-PINTO, 2010, p. 32).

Pela voz de Madalena, surge neste texto uma problemática extrema. O “que deve ter valor"? Será que a contemporaneidade é impossível em virtude de um tipo de valor cada vez mais distante do que é celebrado em Camões? Os versos são incontornáveis, obrigatórios: "Cesse tudo o que a Musa antiga canta,/ Que outro valor mais alto se alevanta.” (Lus, I, 3, 7-8). É certo que Camões não se interessava por cantar o mercantilismo da viagem, muito pelo contrário. O "valor mais alto" é o caráter dos "varões" a serem cantados, e, outrossim, o próprio poema, detentor de "Musa" nova em oposição à "antiga”. Em Gonçalo, no Canto VIII, a ironia chega a seu ápice, pois o que tem "valor" não são tanto os textos ou as obras, mas livros, em sentido proeminentemente material: "A verdade é que Bloom apenas cobiçara,/ maravilhado, uma edição do livro 'Mahabarata' / que parecia ter mais anos / que muitos países" (TAVARES, 2010, p. 347), lê-se na estrofe 56. O local, Shankra, com quem Bloom dialoga, já se precavera contra o forasteiro desde a estrofe 51: "Shankra foi, assim, atirado/ contra Bloom. Bloom quer roubar a tua sabedoria,/ disseram-lhe, e quer roubar os teus livros/ valiosos, decepar a cabeça da tua biblioteca" (TAVARES, 2010, p. 345).

A questão se levanta: a sabedoria se encontra nos livros? Caso sim, que sentido faria uma viagem à Índia, já que livros estrangeiros são facilmente obteníveis sem que o indivíduo precise viajar? Não perco de vista que o fito de Bloom é "sabedoria/ e esquecimento", obtenção e descarte. Tampouco me esqueço de que muita sabedoria em Camões encontra-se fora dos livros - o Velho do Canto IV tem um "saber só de experiências feito" (Lus, IV, 94, 7). No Canto VIII d'Os Lusíadas, Vasco da Gama é sequestrado por um Catual que desobedece inclusive a seu Samorim, líder simpático ao capitão ocidental. Em certos momentos do poema, Gama, que se encontra entre o heroísmo e o humanismo, revela-se mais que, como Ulisses, apenas astuto, revela-se um poderoso interlocutor. Prova disso é o episódio do Adamastor e a despedida dos nautas, imediatamente anterior à fala do Velho. Nesses dois momentos, mesmo acima da interlocução frutífera e ampla, o Gama de Camões demonstra ser um admirável ouvinte - é ouvindo, e não falando, que esse Gama 
consegue que o Gigante dê passagem às naus, e é no diálogo que consegue a simpatia do Samorim.

É sábio o Gama de Camões? Sim, é sábio o Gama de Camões, especialmente quando próximo de um híbrido Camões-Gama, afinadas que são, em diversas ocasiões, essas vozes. É sábio Bloom? Não, tanto que procura a sabedoria e esbarra com seu desejo por livros, não exatamente por obras - obtenção de "sabedoria" e descarte de memórias, mas obtenção (acúmulo?). De passagem: devemos pensar, a partir do nome da personagem, em Harold Bloom, polêmico homem de muitos livros e muita leitura? Paro por aqui. O Bloom de Gonçalo não viaja rumo a uma discutível e desequilibrada troca comercial (nem o Gama de Camões, ao contrário do Gama histórico, e uma crítica histórica fica clara nas tentativas de comércio promovidas pelos orientais no Canto VIII, quase todas lúcidas respostas à aparente proposta portuguesa de troca), mas se vê diante de uma discutível e desequilibrada troca material, como se lê na estrofe 61:

Porém Shankra tinha também olhos

e com eles havia visto, na pequena

mala de Bloom, duas preciosidades,

dois livros que a velha Europa havia

inventado: "Cartas a Lucílio", de

Sêneca, em edição tão antiga

e com as páginas de tal forma a desfazer-se

que quase se diria serem páginas não materiais mas espirituais, e ainda - vira Shankra - o teatro completo

de Sófocles, também em edição rara.

(TAVARES, 2010, p. 349)

Os três livros em negociação guardam textos antigos, anteriores à capitalização do livro enquanto objeto. E o fato é esse: os três livros - um tem o grande épico hindu, pleno de religiosidade, outro, epístolas recheadas de preceitos éticos, e o terceiro, um compêndio teatral que reúne textos fundadores do pensamento ocidental - encontram-se em negociação, como fossem objetos despidos de qualquer caráter supramercantil. Os textos são antigos, muito mais antigos que Os Lusíadas, epopeia cercada por uma sociedade mercantil 
e narradora duma viagem que, historicamente, teve objetivos comerciais. Por outro lado, o grande interesse camoniano, muito já se disse desde, pelo menos, Jorge de Sena, foi o da recepção de sua obra, que acarretaria um entendimento mais fecundo de diversas coisas muito importantes - os "varões" enquanto povo, o amor enquanto utopia trágica, a interlocução enquanto fala e escuta, ou seja, troca para além de qualquer fazenda.

Um pouco por isso, um pouco por/ para outras razões, Fiama Hasse Pais Brandão pôde formular: "o Poema é também o percurso da experiência mística do próprio poeta” (BRANDÃO, 2007, p. 103). É evidente que não existe experiência mística em Uma viagem à Índia, nem sabedoria: "Já não há sábios, há leitores - exclama Bloom. Tudo é paginável:/ a inteligência, a ciência, a religião" (TAVARES, 2010, p. 356), lê-se na estrofe 79 do Canto VIII. Se não há sábios, não há sabedoria acessível pela interlocução; se tudo se pode paginar num universo de livros sem alma, tudo se pode vender e comprar, inclusive "a religião". Bloom, na estrofe seguinte, aceita a "troca dos livros" (TAVARES, 2010, p. 356), mas depois seu dinheiro é roubado por homens de Shankra. Mas Bloom roubou de Shankra - é importante dizer agora, pois já deveria ter dito antes: Shankra é um sábio indiano, que Bloom procura ao procurar sabedoria - um cordão de ouro, e a devolução do objeto ao indiano permite ao ocidental reaver seus livros, já no Canto IX.

O final do Canto VIII de Uma viagem à Índia é uma reflexão acerca do dinheiro, exatamente como o é o encerramento do Canto VIII d'Os Lusíadas, cujo locutor é o próprio Camões. Cito ambas as estrofes finais, as respectivas 99:

Ah, tão mau é o dinheiro, tão mau e horrível

quando não me pertence, pensa Bloom,

enquanto passa directamente, sem intermediários,

verbas da ignóbil Europa

para a sábia, sensata e receptiva Índia.

(TAVARES, 2010, p. 363)

Este interpreta mais que sutilmente

Os textos; este faz e desfaz leis;

Este causa os perjúrios entre a gente

E mil vezes tiranos torna os Reis. 
Até os que só a Deus omnipotente

Se dedicam, mil vezes ouvireis

Que corrompe este encantador, e ilude;

Mas não sem cor, contudo, de virtude.

(Lus, VIII, 99)

Em Camões, o religioso é corruptível, mas a religião, não, já “Que o bom Religioso verdadeiro/ Glória vã não pretende nem dinheiro.” (Lus, X, 150, 7-8) - pensando melhor, a religião talvez também o seja, mas não o que Fiama chama de "experiência mística do próprio poeta". A Índia, turística, de fato obtém "verbas da ignóbil Europa", que, por sua vez, quando turística, obtém "verbas" de outras origens. O já citado ensaio de Madalena Vaz-Pinto intitula-se "Gonçalo Tavares: o filho mais desenvolto de Álvaro de Campos? Convocação de textos". O diálogo estabelecido é com o famoso texto de Eduardo Lourenço intitulado "Uma literatura desenvolta ou os filhos de Álvaro de Campos", presente em $O$ canto do signo. Era bom pretexto para eu convidar o Campos do "Opiário", especialmente por causa de uma estrofe: "Pertenço a um gênero de portugueses / Que depois de estar a Índia descoberta/ Ficaram sem trabalho. A morte é certa./ Tenho pensado nisto muita vezes." (Pessoa, 1999, p. 12). A que "gênero" pertence Bloom? Que "trabalho" tem? Que história? Que Índia descobre em Shankra et caterva?

No entanto, não lidarei com isso, infelizmente. Este ensaio começa a terminar, e devo enfrentar o que chamei de ironia extratextual em torno de Uma viagem à Índia - esse texto tão crítico e irônico em relação a dinheiro, texto que problematiza a ideia de valor dentro e fora da literatura, foi escrito por Gonçalo M. Tavares. Quem é ele? A primeira informação que nos dá a biobibligrafia presente em Uma viagem à Índia é que o escritor nasceu em 1970; logo após, lê-se uma lista de prêmios recebidos por Gonçalo, e, ao final, a grande quantidade de traduções dedicadas a livros seus. O texto possui dezenove linhas, das quais quinze dão conta de premiações, e é uma identificação, decerto não escrita pelo próprio escritor. Mas, como está em livro seu, é por ele chancelada, é, portanto, dele. E diz respeito a prêmios, que dizem respeito, por sua vez, a um mérito não necessariamente advindo do mercado (ainda que muitas vezes advindo), mas necessariamente abraçado pelo mercado. 
A parte final deste meu texto, deixo claro, apenas problematiza um desconforto que não me passa despercebido, e que não finjo desconhecer: Gonçalo M. Tavares é um sucesso, e a pergunta se me impõe: é possível ser um sucesso nos dias de hoje sem que isso cobre um preço? É possível que um sucesso hodierno logre passar ileso àquilo que critica? Quem é Gonçalo M. Tavares? Acima da biobibliografia, uma foto do escritor. Vê-se Gonçalo em ambiente um tanto inóspito, que lembra uma fábrica abandonada, e atrás do homem, de um lado, rolos de papel mal-ajambrados e, do outro, escombros - nada do ambiente convencional do escritor, com livros atrás do corpo que escreveu. O cenário pode-se definir entre o desolador e o teatral, e o homem à frente do cenário, personagem. Não penso agora, de modo algum, em narrador, subjetivação ou subjetivação problemática, penso numa figuração cheia de estilo e que pretende aparentar o contrário, o despojamento.

Tudo se acentua porque Gonçalo M. Tavares está vestido sem grande apuro, apresenta uma barba mal aparada e cabelos despenteados, além de, atrás dos óculos, um olhar tão sério que quase triste. Sem dúvida, é uma personagem, cuja função é criar um sentido completamente extrínseco à obra suportada pelo livro, e através desse sentido, criar algo da ordem da credibilidade ou da diferença, ou do espetáculo - faltava esse vocábulo, no sentido cunhado por Guy Debord, e o pensador francês, sabemos, estava muito interessado na imagem: "O espetáculo é o capital em tal grau de acumulação que se torna imagem” (DEBORD, 1997, p. 25). Não quero dizer, longe de mim, que seja possível fazer uma ligação direta entre "acumulação de capital" e Gonçalo M. Tavares. Mas a referida imagem do escritor é uma “imagem”, e, penso, com vocação espetacular.

O êxito de Gonçalo M. Tavares tem muitas evidências. Uma delas é fazer parte o escritor da lista de "Dez figuras que marcaram o ano", feita pelo Jornal Público em finais de 2010. O texto de Isabel Coutinho cita a escritora francesa Elisabeth Barillé: "Vai Gonçalo M. Tavares tornar-se um produto de exportação tal como o vinho do Porto e a saudade?, perguntava ela. A resposta só pode ser: sim." (COUTINHO, 2010). As palavras por vezes revelam mais do que querem os que as põem no mundo: "produto de exportação", li, e produto, em contexto como o citado, é produto - se a "saudade" não é mercadoria, garrafas de vinho do Porto o são; e Gonçalo M. Tavares? Sua obra, diz-me a lista que encerra a edição de Uma viagem à Índia, tem efetivas divisões, para além dos gêneros que contempla: "O Reino", "O Bairro", "Enciclopédia", 
etc. Dentro de "O Reino", romances como Jerusalém e Aprender a rezar na era da técnica; a "Enciclopédia" compõe-se de Breves notas sobre a ciência, Breves notas sobre o medo e Breves notas sobre as ligações. Já o "Bairro" é onde se encontram os Senhores: O Senhor Valéry, O Senhor Walser, etc. Seria excessivo ver nessa divisão uma espécie de supermercado para o leitor culto? Há prateleiras, em cada uma um tipo de "produto" para "exportação" e consumo interno...

Tudo isso me soa irônico, digo outra vez, porque Uma viagem à Índia é texto crítico e melancólico, cercado, não obstante, por um êxito muito contente, muito bem acabado. Haverá aí uma aporia, um paradoxo, haverá o enfraquecimento dos sentidos da obra? Não sei, mas o mundo circundante me obriga a pensar nessas coisas. Ainda na matéria de Isabel Coutinho, leio que Zeferino Coelho (editor da Caminho, que hoje pertence ao poderoso Grupo Leya) e Vasco Graça Moura supõem em Gonçalo M. Tavares um vindouro Nobel. Quando a premiação acontecer, espero que muitas das perguntas aqui feitas ganhem novos formuladores. Afinal, a "ironia não salva, mas ressalva". Ressalvemos.

\section{Referências bibliográficas}

BAKHTIN, Mikhail. Problemas da poética de Dostoiévski. $3^{\mathrm{a}}$. ed. Tradução de Paulo Bezerra. Rio de Janeiro: Forense Universitária, 2002.

BRAIT, Beth. Ironia em perspectiva polifônica. Campinas: Unicamp, 1996.

BRANDÃO, Fiama Hasse Pais. O labirinto camoniano e outros labirintos. $2^{\mathrm{a}}$. ed. Lisboa: Teorema, 2007.

CAMÕES, Luís de. Os Lusíadas. Edição de Emanuel Paulo Ramos. Porto: Porto Editora, 1978.

COUTINHO, Isabel. Dez figuras portuguesas que marcaram o ano: o escritor Gonçalo M. Tavares. Jornal Público, Lisboa, 22/12/2010. Disponível em: <http://www.publico.pt/Cultura/o-escritor-goncalo-m-tavares_1472125>. Visitado em 23/12/2010.

DEBORD, Guy. A sociedade do espetáculo. Comentários sobre a sociedade do espetáculo. Tradução de Estela dos Santos Abreu. Rio de Janeiro: Contraponto, 1997.

HELDER, Herberto. Photomaton \& vox. 3a. ed. Lisboa: Assírio \& Alvim, 1995.

LOURENÇO, Eduardo. Uma viagem no coração do caos. Prefácio a TAVARES, Gonçalo M. Uma viagem à Índia. Lisboa: Caminho, 2010, p. 9-20.

PESSOA, Fernando. Poemas de Álvaro de Campos. Edição de Cleonice Berardinelli. Rio de Janeiro: Nova Fronteira, 1999. 
TAVARES, Gonçalo M. Uma viagem à Índia. Lisboa: Caminho, 2010.

VAZ-PINTO, Madalena. Gonçalo Tavares: o filho mais desenvolto de Álvaro de Campos? Convocação de textos. Abril - Revista do Núcleo de Estudos de Literatura Portuguesa e Africana da UFF, no 4, Literatura e valor, Niterói, NEPA/UFF, p. 31-39, abril de 2010.

VERDE, Cesário. Poemas reunidos. Introdução e notas de Mario Higa. São Paulo: Ateliê Editorial, 2010.

Recebido em 03 de maio e aprovado em 06 de junho de 2011. 